\title{
A dinâmica institucional da interação UFSC-Petrobras para a inovação
}

\author{
* Paola Azevedo iD \\ Universidade Federal de Santa Catarina (UFSC), Florianópolis (SC), Brasil \\ E-mail: pazevedo4@gmail.com \\ * Silvio Antônio Ferraz Cario (D) \\ Universidade Federal de Santa Catarina (UFSC), Florianópolis (SC), Brasil \\ E-mail: fecario@yahoo.com.br
}

\section{Resumo}

Este trabalho tem como objetivo avaliar a dinâmica institucional da interação Universidade Federal de Santa Catarina (UFSC) e Petrobras para a inovação. Adotou-se como base teórica a perspectiva institucionalista-evolucionária. Efetuaram-se entrevistas com pesquisadores da UFSC e com gerentes da Petrobras que realizam a interação. Dentre os principais resultados desta dinâmica institucional analisada, destacam-se a relevância do relacionamento pessoal, a constante busca por pesquisadores de referência e de especialistas, a importância da institucionalização da interação Universidade-empresa (U-E), do processo histórico de construção de parceria, do estabelecimento de regras e regulamentaçóes de Pesquisa e Desenvolvimento (P\&D) da UFSC e da Agência Nacional do Petróleo (ANP), da criação do termo de cooperação e do Sistema de Gestão de Investimentos em Tecnologia (Sigitec) e a criação e a manutenção de infraestrutura de ponta, as quais consolidaram o processo de interação com a UFSC nos últimos trinta anos.

Palavras-chave | Interação Universidade-Empresa; Perspectivas institucionalista e evolucionária; Dinâmica institucional; UFSC; Petrobras. 


\title{
The institutional dynamics of UFSC and \\ Petrobras interaction for innovation
}

\begin{abstract}
This a rticle a ims to e valuate the institutional dynamics of interaction between Federal University of Santa Catarina (UFSC) and Petrobras for innovation. The institutionalistevolutionary perspectives were adopted as a theoretical basis. The interviews were conducted with researchers from UFSC and managers from Petrobras who carry out the interaction. Among the main results of this analyzed institutional dynamics are the relevance of the personal relationship, the constant search for reference researchers and specialists, the importance of institutionalizing the University-company interaction (UC), the historical process of building partnership, the establishment of rules and regulations for research and development (R\&D) at UFSC and the National Petroleum Agency (ANP), the creation of the cooperation term and the Technology Investment Management System (SIGITEC) and the creation and maintenance of state-of-the-art infrastructure, which consolidated the interaction process with UFSC in the last thirty years.
\end{abstract}

KeYwords | University-Industry Interaction; Evolutionary-Institutional Perspectives; Institutional Dynamics; UFSC; Petrobras. 


\section{Introdução}

O Sistema Nacional de Inovação (SNI) é compreendido como alicerce essencial do desenvolvimento econômico, pois é constituído por organizações e instituições econômicas, sociais e políticas, cuja trajetória interativa numa perspectiva histórica é determinante no desempenho das economias industrializadas (PEREIRA; DATHEIN, 2012). Neste contexto, as interaçôes U-E são elementos essenciais no SNI, uma vez que a articulação destes entes para realizaçáo de parcerias e projetos de $\mathrm{P} \& \mathrm{D}$ promove o avanço tecnológico. As universidades desenvolvem o conhecimento para a inovação, fornecem respostas científicas às demandas das empresas e estas transformam o conhecimento em novas tecnologias, dando origem a novas questóes de pesquisa.

A relevância da interação U-E para o desenvolvimento da inovação suscita a compreensão deste fenômeno. Dentre os artigos internacionais mais citados em periódicos estrangeiros que tratam do tema interação U-E, conforme Web of Science, de 2000 a 2015, destacam-se os de Gubrandsen e Smeby (2005), D`Este e Patel (2007) e Mowery e Sampat (2007), os quais debatem esta interação sob as ópticas da tríplice hélice e do SNI. Dentre os livros, enfatizam-se os organizados por Suzigan, Albuquerque e Cario (2011) e por Garcia, Rapini e Cario (2018), que deram ênfase à interação U-E em busca de inovação, sob a perspectiva teórica neoschumpeteriana.

Diante dos resultados relacionados às pesquisas sobre a interação U-E, sugere-se neste estudo a compreensão deste fenômeno a partir das perspectivas institucionalista e evolucionária. Estas abordagens propostas ampliam as possibilidades de análises até então náo discutidas por outros autores, permitindo compreender os acordos, os procedimentos de cooperação, bem como os mecanismos de coordenaçẫo, rotinas, padróes de organizaçáo da produção e divisão do trabalho, com intuito de entender de que maneira as atividades vinculadas a esta parceria se desenvolveram ao longo de décadas e se tornaram essenciais ao desenvolvimento de tecnologias de fronteira no país. Para Nelson e Nelson (2002), estas correntes teóricas são dotadas de pressupostos em comum e são complementares no entendimento da inovação, pois as instituiçôes propiciam acréscimos de conhecimento que se traduzem em aprimoramentos tecnológicos.

Nesta perspectiva, procura-se compreender a interação U-E, em estudo de caso, envolvendo a UFSC e a Petrobras, atores estratégicos do SNI brasileiro. A Petrobras é uma transnacional pública que mais investe em $P \& D$ no país e interage de forma contínua com instituiçóes de pesquisa. Segundo a ANP, de 1998 até 2018, 
a Petrobras foi responsável por mais de $90 \%$ do investimento em P\&D realizado no Setor de Petróleo e Gás Brasileiro, decorrentes de contratos assinados sob o regime de concessão e cessão onerosa, totalizando R \$ 13,9 bilhóes. A UFSC é uma das universidades que mais recebem recursos da Petrobras para realização de P\&D, e tem uma trajetória histórica e articulada de interação para o desenvolvimento da inovação com a empresa de aproximadamente trinta anos.

A fim de atender o objetivo de avaliar a dinâmica institucional da interação UFSC e Petrobras para a inovação, o presente texto encontra-se dividido em seis seçóes: a introdução composta pela problematização e objetivo da pesquisa; o referencial teórico-analítico sobre interação U-E na perspectiva institucionalista-evolucionária; a metodologia elucidando a realização da pesquisa; a caracterização dos laboratórios e pesquisas da UFSC em interação com a Petrobras; a análise da dinâmica institucional da interação UFSC e Petrobras a partir das variáveis: hábitos, instituições, tecnologias físicas e tecnologias sociais; e, por fim, a conclusão.

\section{A interação universidade-empresa na perspectiva teórica institucionalista-evolucionária}

As interaçóes de universidades, empresas, governos e outros componentes do sistema de inovação compóem o marco de referência nos estudos acerca do processo inovativo e, em função dos diferentes arranjos existentes, derivam de distintos enfoques analíticos conceituais (CARIO; LEMOS SIMONINI, 2011). A constituição destas interaçóes é dotada de uma trajetória histórica dependente de investimentos e maturação de cinco fatores: arranjos monetário-financeiros que viabilizem o financiamento de universidades, institutos de pesquisa e empresas; criação de instituiçóes importantes, como universidades, institutos de pesquisa, empresas e seus laboratórios de P\&D; elaboração de mecanismos que propiciem interaçóes; desenvolvimento de interações dos atores envolvidos; e concretização da interação por meio de relaçóes de confiança entre as partes (SUZIGAN; ALBUQUERQUE; CARIO, 2011).

Estas interações fazem partem do sistema de inovação, que visa ao desenvolvimento, difusão e utilização da inovação. Nesse ambiente sistêmico, as inovações tecnológicas, organizacionais e institucionais são definidas e conformadas a partir da relação complexa e dos recursos existentes e se tornam reflexo da posição das economias nacionais. Por meio do SNI é possível identificar a maneira adotada pelo Estado para estabelecimento de políticas e prioridades ao longo dos anos, e o modo 
pelo qual este reage a condiçôes favoráveis dos mercados nacionais e internacionais para propiciar o desempenho econômico (NELSON, 2006).

O surgimento e a consolidaçáo do paradigma e trajetória tecnológica nos sistemas de inovação ocorrem a partir de procedimentos inovativos de busca, rotina e seleçấo. O processo de busca trata-se de um conjunto de atividades e estratégias desenvolvido para aperfeiçoar tecnologia e aproveitar as possibilidades existentes, avaliando as possíveis mudanças nos produtos e processos. A rotina, por sua vez, é um comportamento de caráter tácito de difícil captura e codificação e propicia a criação de uma memória em relação às açóes da empresa, que gera uma atuação mais efetiva por parte desta (NELSON, 2006). A seleçấo corresponde ao mecanismo de eleição das inovaçóes exercido pelo ambiente, no qual se destaca a atuação do mercado como elemento central, ainda que o processo seja beneficiado com contribuiçôes de empresas e instituiçóes (DOSI, 2006; NELSON; WINTER, 2006).

Desenvolve-se no contexto do sistema de inovação o processo de aprendizagem tecnológica, que pode ser elucidado a partir da compreensão de que o ambiente econômico está em constante evolução. Sob a economia do aprendizado, conforme Johnson e Lundvall (2005), aceleram-se mudanças técnicas, sociais e econômicas que subsidiam a formação e destruiçâo do conhecimento especializado. Fica evidenciada sob esta perspectiva a relevância da habilidade de aprender no desempenho econômico, tanto do indivíduo como da organização.

A ampliação da perspectiva dos sistemas de inovação, no âmbito da teoria evolucionária econômica, pode ocorrer pela utilização de elementos da análise institucional (NELSON; NELSON, 2002). No SNI a análise está voltada principalmente para a interação entre os atores econômicos, políticos e sociais, os quais propiciam capacitaçôes e a propagação de inovaçóes em um país (TIGRE, 2005). O desempenho deste sistema relaciona-se então a um "processo evolucionário", no qual a trajetória engloba aspectos relacionados à tecnologia, ao conhecimento, aos atores (empresas, laboratórios, governos, universidades e institutos de pesquisa) e aos arranjos institucionais (MALERBA, 2003). Nesse sistema, ocorrem interaçôes e ligaçóes entre os atores participantes: pessoas e universidades, empresas e governo; instituições financeiras e empresas; governo e organizaçóes inovativas entre outras, com propósito voltado ao desenvolvimento inovativo (NIOSI et al., 1992; NIOSI, 2002).

A compreensão de maneira mais ampla do SNI, a partir da abordagem institucionalista, perpassa inicialmente pelo entendimento das categorias essenciais por meio das quais a teoria institucionalista é constituída, tais como: os instintos, 
os hábitos, as instituições e a mudança institucional. Os instintos são propensôes inatas que estão presentes e não se manifestam de forma clara na conduta humana e definem o objetivo fim do comportamento, como por exemplo, o instinto de trabalho eficaz, que leva a pessoa a optar pelas formas e os meios propícios para atingir determinado objetivo (MONASTÉRIO, 1998; HODGSON, 2010).

Os hábitos são provenientes de ações, pensamentos e comportamentos repetidos que se traduzem na probabilidade de se comportar de determinada forma diante de certas ocasióes particulares e permitem, assim, um aprendizado mais rápido, muitas vezes relacionado com circunstâncias novas. Os hábitos desencadeiam-se a partir de um estímulo ou contexto e desenvolvem-se em um ambiente social (HODGSON, 2010, 2011).

O conjunto de hábitos origina as instituições, em sentido amplo, e são estas que propiciam poder e autoridade normativa estável. Na medida em que reproduzem os hábitos, as instituições geram mecanismos de aceitação normativa (HODGSON, 2011) e também podem ser vistas como agentes de mudança, pois modelam o conhecimento, bem como sua aplicação à resolução de problemas. Atuam na criação de um contexto adequado para o avanço tecnológico e à continuidade do crescimento econômico. São essenciais para o processo inovativo, pois definem trajetórias de crescimento nos diferentes ambientes, bem como meios que dão suporte a padróes de interação particulares. Caracterizam-se como "regras do jogo", padrão de comportamento socialmente acordado e maneiras de acumulaçáo do conhecimento (CASTELLI; CONCEIÇÃO, 2014).

Para Edquist (2004), as instituições têm três funções essenciais em relação às inovações: redução da incerteza e geração de informações; administração de conflitos e cooperação; e provimento de incentivos. Especificamente o provimento de recursos por parte das instituiçóes refere-se à criação de possibilidades de comunicação e cooperação entre indivíduos e empresas com agências do governo. A institucionalização é importante, pois possibilita que os hábitos atuais se constituam sobre uma base institucional já formada. Assim, as instituições podem adquirir as seguintes dimensóes: instituições como princípios essenciais sobre os quais os outros hábitos de pensamento são construídos; instituições como normas sociais; e instituições estabelecidas na forma de leis (MONASTERIO, 1998).

Nessa perspectiva, para North (1991) as instituiçóes podem assumir o papel de restrições informais (convençóes, códigos de conduta, tabus, costumes, tradiçôes, sançóes) ou regras formais (leis, constituiçóes e direitos de propriedade). As restriçóes informais são decorrentes da informação socialmente transmitida e representam 
parte da herança cultural. Decorrem de costumes, tradiçóes ou códigos de conduta e são mais resistentes e difíceis de serem alteradas. Estas limitaçóes culturais ligam o passado, o presente e o futuro e sáo elementos essenciais para compreensão da mudança sob a perspectiva histórica (NORTH, 1990).

As regras, por sua vez, são condutas predeterminadas, por meio das quais os agentes podem agir de maneira consciente ou inconsciente (HODGSON, 2001). Estas abrangem normas de comportamento e convençóes sociais, bem como as regras legais. A regra pode tornar-se um hábito na medida em que é reiterada. As regras formais integram a complexidade das sociedades e têm a capacidade de complementar e aumentar a eficácia das restriçóes informais e permitir que estas sofram alteraçôes, rescisôes ou sejam substituídas. As tensôes existentes entre as regras formais modificadas e as restrições informais persistentes influenciam as transformaçôes na economia. As regras estão em constante mutação, dão forma às instituiçóes e relacionam-se ao aprendizado contínuo, que é path-dependent, enraizado e cumulativo (CONCEIÇÃO, 2002).

Para Nelson e Sampat (2001), em virtude das diversas concepçóes existentes em relação a instituiçóes, é crucial analisar o processo e como ocorre a atividade econômica, focando naquilo que as instituiçóes realizam e, neste sentido, sugere o conceito de tecnologia social, a qual envolve a padronização da interação humana. O entendimento das tecnologias permite a compreensão da dinâmica institucional. Para Nelson (2008) a efetividade das atividades econômicas e o crescimento econômico correlacionam-se às tecnologias física e social (NELSON, 2008). A primeira é ligada a procedimentos a serem realizados, os quais são normalmente dependentes de insumos e equipamentos. A segunda diz respeito a mecanismos de coordenação, rotinas, padrões de organização da produção e divisão do trabalho.

Transportando a ideia de tecnologias físicas e sociais para um sistema de P\&D, identificam-se os laboratórios, procedimentos, centros de pesquisa, por exemplo, como tecnologias físicas. A coordenação e a divisão do trabalho entre os pesquisadores são consideradas tecnologias sociais (CONCEIÇÃO, 2009). As tecnologias físicas e sociais são influenciadas por aspectos como normas, leis, costumes, dentre outros que promovem sua padronização. Quando as tecnologias sociais são institucionalizadas criam condiçôes para a evolução das tecnologias físicas, e a coevolução é crucial para a consolidação dos sistemas de inovação e promoção do crescimento econômico (NELSON, 2008; PEREIRA; DATHEIN, 2012).

As instituiçôes dáo forma ao crescimento do conhecimento científico, tecnológico e social (METCALFE, 2001) e são entendidas como estruturas e forças 
que moldam e sustentam as tecnologias sociais (NELSON, 2008). As instituiçóes definem trajetórias de crescimento diversificadas nos diferentes ambientes nacionais. Além disso, criam, possibilitam ou exercem influência sobre: as inovaçóes tecnológicas, a organização das empresas, o processo de trabalho, as políticas macroeconômicas e o padrão de competitividade, os quais propiciam a articulação entre o crescimento e o desenvolvimento econômico (CONCEIÇÃO, 2002).

\section{Metodologia}

Para compreender a dinâmica institucional da interação UFSC e Petrobras voltada à inovação, foi realizado, no período de dezembro de 2014 a dezembro de 2015 , o mapeamento de todos os projetos elaborados por estas duas instituiçóes através dos sites das fundações que intermedeiam os projetos de P\&D, que são a Fundação de Ensino e Engenharia de Santa Catarina (Feesc) e a Fundação de Amparo à Pesquisa e Extensão Universitária (Fapeu). Para validação dos projetos em parceria foi consultado o Departamento de Inovação Tecnológica (DIT) da UFSC, atualmente denominado Secretaria de Inovação (Sinova).

Identificaram-se 27 laboratórios de pesquisa em interação com a Petrobras, os quais totalizaram 59 projetos de pesquisa neste período. A seleção dos coordenadores de laboratórios participantes da pesquisa ocorreu por acessibilidade e levando-se em conta os laboratórios que interagem com a empresa há mais de vinte anos e, juntos, respondem por mais de $50 \%$ dos projetos realizados em parceria com a Petrobras: o Laboratório de Meios Porosos e Propriedades Termofísicas (LMPT), oito projetos; Laboratório de Metrologia e Automação (Labmetro), quatro projetos; Laboratório de Tubos de Calor (Labtucal), quatro projetos; Laboratório de Remediação de Águas Subterrâneas (Remas), três projetos; Laboratório de Pesquisa em Refrigeração e Termofísica (Polo), três projetos; e, Laboratório de Automação de Campos Inteligentes (Laci), dois projetos.

Selecionados os laboratórios, optou-se pela realização da entrevista semiestruturada com os pesquisadores de cada um destes, visto que os projetos são vinculados a cada laboratório. Além dos pesquisadores, foi entrevistada a diretora do DIT, atual Sinova, setor pelo qual são assinados os contratos de interação. Na Petrobras, dois gerentes vinculados à interação com os laboratórios da UFSC foram entrevistados. As entrevistas ocorreram de agosto de 2015 a janeiro de 2016. A identificação dos entrevistados ao longo do estudo foi realizada por meio da classificação E1 a E9, dos quais E1 a E7 vinculados à UFSC e E8 e E9 à Petrobras. 
Os dados foram analisados por meio da análise de conteúdo, com base em categorias previamente definidas, baseadas na perspectiva institucionalista-evolucionária, e com o apoio do software de análise de dados qualitativos NVIVO. As categorias fechadas que expressaram a análise da dinâmica institucional da interação em estudo foram: hábitos (caráter pessoal das açôes - maneiras de pensar, de agir), instituiçôes (caráter coletivo das ações - regras, leis), tecnologias físicas: procedimentos de trabalho e sua estrutura física (laboratórios, insumos, materiais, equipamentos), e tecnologias sociais (formatos de organização do trabalho; divisão do trabalho entre os pesquisadores; estruturas de coordenação e direção).

\section{Identificação dos laboratórios de pesquisa da UFSC e resultados ino- vativos da interação com a Petrobras}

Dos laboratórios da UFSC que interagem com a Petrobras, através de projetos de P\&D para o desenvolvimento de inovação no Setor de Petróleo e Gás, seis deles relacionam-se com a empresa há vinte anos, como o LMPT, Labmetro, o Labutcal o Polo, o Remas e o Laci. Atualmente, o Labtucal realiza pesquisas na área de energia solar e transferência de calor aplicada, incluindo o desenvolvimento de tecnologia de tubos de calor. No Polo, os estudos voltam-se para o aprimoramento dos conceitos e aperfeiçoamento do desempenho de componentes e sistemas de refrigeração, tornando o laboratório uma referência mundial em $\mathrm{P} \& \mathrm{D}$ em refrigeração e termofísica. O Remas investiga a contaminação de solos e águas subterrâneas por combustíveis de petróleo e biocombustíveis (tecnologias de biorremediação e modelagem matemática). O LMPT desenvolve atividades na área de materiais porosos, interação de fluidos e entre fluidos e superfícies sólidas e instrumentos para medição de variáveis térmicas. O Labmetro possui destaque nas áreas de metrologia, instrumentação e automação da medição. E o Laci atua na área de otimização matemática, controle distribuído e otimização de sistemas de produção de petróleo e gás.

Dentre as inovaçóes criadas a partir dessa parceria citam-se duas tecnologias. Uma das tecnologias criadas refere-se aos Sistemas Porosos Multiescalares, um projeto correlacionado ao tema rocha digital aplicado em sistemas porosos com múltiplas porosidades, especificamente carbonatos. A outra tecnologia criada refere-se ao projeto de avaliação do carregamento em dutos a partir das tensões residuais, com propósito de avaliar a integridade dos dutos e o nível de risco de acidentes, em trechos sujeitos a movimentaçóes do solo e encostas. 


\section{A dinâmica institucional da interação UFSC e Petrobras}

\subsection{Hábitos}

Os hábitos decorrem de açóes, pensamentos e comportamentos e, na medida em que se repetem, podem levar a um comportamento determinado frente a ocasiôes particulares, permitindo um aprendizado mais rápido (HODGSON, 2010). Assim, através dos hábitos pode-se identificar e entender de que maneira os comportamentos individuais interferem na interação U-E, no sentido de realizar a aproximação, bem como manter parcerias no decorrer do tempo.

A partir da identificação de temas estratégicos na área de petróleo e gás, a empresa formou redes de pesquisadores e instituiçôes distribuídas pelo país, conforme dizeres dos gerentes: "Os primeiros projetos são da década de 1990 e estavam ligados à especialidade dos pesquisadores e às necessidades da empresa [E9]". "Foram identificados pesquisadores cuja especialidade estava ligada aos desafios tecnológicos da empresa [E8]". Conforme os gerentes da Petrobras, a trajetória de interação com a UFSC foi marcada por uma busca incessante por pesquisadores de referência, especialistas no tema da indústria, o que culminou também na formaçáo contínua de novos pesquisadores e criação de cursos na área de atuação da empresa.

Pode-se, também, constatar que a formação e os relacionamentos pessoais de cada pesquisador interferiram diretamente no estabelecimento da parceria, em virtude do conhecimento adquirido ao longo dos anos na academia e seu próprio reconhecimento dentro das áreas de interesse. Essa discussão alinha-se ao exposto por Cario, Lemos e Simonini (2011), os quais verificaram que na interação U-E é essencial a consideração de aspectos informais, tais como: o relacionamento pessoal, proximidade com as empresas, cultura e história anterior.

A busca por pesquisadores de referência se traduziu em parceria, em novos cursos e aumento de pesquisadores e profissionais relacionados à área, elevando e qualificando os grupos de pesquisa da UFSC que são interligados à Petrobras. Nessa via, desenvolvem-se procedimentos de busca dentro de um conjunto de atividades e estratégias da empresa com o intuito de obter vantagem competitiva e aperfeiçoar sua tecnologia para aproveitar as oportunidades existentes (NELSON, 2006). O processo de busca da empresa pelos pesquisadores com competência, formaçáo e experiência foi essencial para a interação entre UFSC e Petrobras se consolidar ao longo dos anos, bem como gerar novas tecnologias. 
Os gerentes da Petrobras corroboram com os pesquisadores na UFSC no que se refere à busca de cursos de Pós-Graduação, visto que se torna um movimento esperado procurar a capacitaçáo em locais nos quais há certeza da qualidade do parceiro tecnológico, "Os pesquisadores da Petrobras buscam cursos de Pós-Graduação na UFSC e outras ICTs, pois conhecem os parceiros e a qualidade da pesquisa [E8]". A formação dos grupos de pesquisa é influenciada pelos pesquisadores, os quais se aproximam em virtude do interesse pelo tema. Este interesse se alinha ao instinto de trabalho eficaz que, segundo Veblen, é o instinto que leva a pessoa a optar pelas formas e os meios propícios para atingir determinado objetivo (MONASTERIO, 1998; HODGSON, 2010). A partir da intenção cria-se forma rotineira para alcançar o que deseja, o que gera o hábito de comportamento. Nesse contexto, cita-se o hábito de aproximação dos pesquisadores, formando grupos de especialistas para atender interesses de pesquisa comuns.

Os relacionamentos pessoais são essenciais para realização dos contatos com a Petrobras, bem como para a manutenção desta interação, conforme o depoimento do pesquisador: "É uma relação de confiança, competência estabelecida, histórico de pesquisa [E5]". O gerente da Petrobras também ressalta a importância da confiança dos parceiros, a qual perpassa por estes relacionamentos pessoais que, historicamente, são construídos ao longo do desenvolvimento dos projetos e de resultados positivos, possibilitando a criação de uma linguagem intermediária entre a Universidade e empresa. Nesse ponto, Suzigan, Albuquerque e Cairo (2011) destacam o processo histórico na construção das interaçóes, o qual está vinculado ao investimento e maturação em vários elementos, dentre eles, a consolidação da interação, gerando relaçóes de confiança e propiciando um feedback positivo entre as partes.

Embora reconheçam a relevância do apoio institucional na interação U-E e os avanços conquistados através do estabelecimento de um termo de cooperação padrão celebrado entre as Universidades e a Petrobras em âmbito nacional, os pesquisadores ressaltaram ameaças neste processo, como ausência de apoio administrativo nos projetos, despreparo do pesquisador para gerenciar o projeto e burocracia. No caso da empresa, a ameaça de interaçáo está relacionada à burocracia e excessos de auditorias relacionadas aos órgãos de controle do governo e à agência reguladora, o que atrapalha o processo de interação e o desenvolvimento da pesquisa, conforme segue: "Há um excesso de burocracia que atrasa os projetos de interação, parece algo institucionalizado [E9]".

A burocracia, expressa através de procedimentos e regras, gera hábitos de comportamento, que se manifestam na interação U-E. Esta constitui como algo 
enraizado, influenciando rota de desenvolvimento constituída ao longo dos anos. Nessa perspectiva, a institucionalização da interação UFSC e Petrobras possibilitou definição clara de quais são os caminhos a serem seguidos, requerimentos a serem atendidos, prazos contratuais entre outros procedimentos, conduzindo os pesquisadores a um comportamento coletivo, que seja institucionalizado e não prescinda apenas de relaçóes pessoais. Nesse sentido, as instituiçóes são vistas como agentes de mudança e são essenciais na criação de um contexto adequado para o avanço tecnológico e à continuidade do crescimento econômico (CASTELLI; CONCEIÇÃO, 2014).

FIGURA 1

Hábitos da interação UFSC e Petrobras, 2016

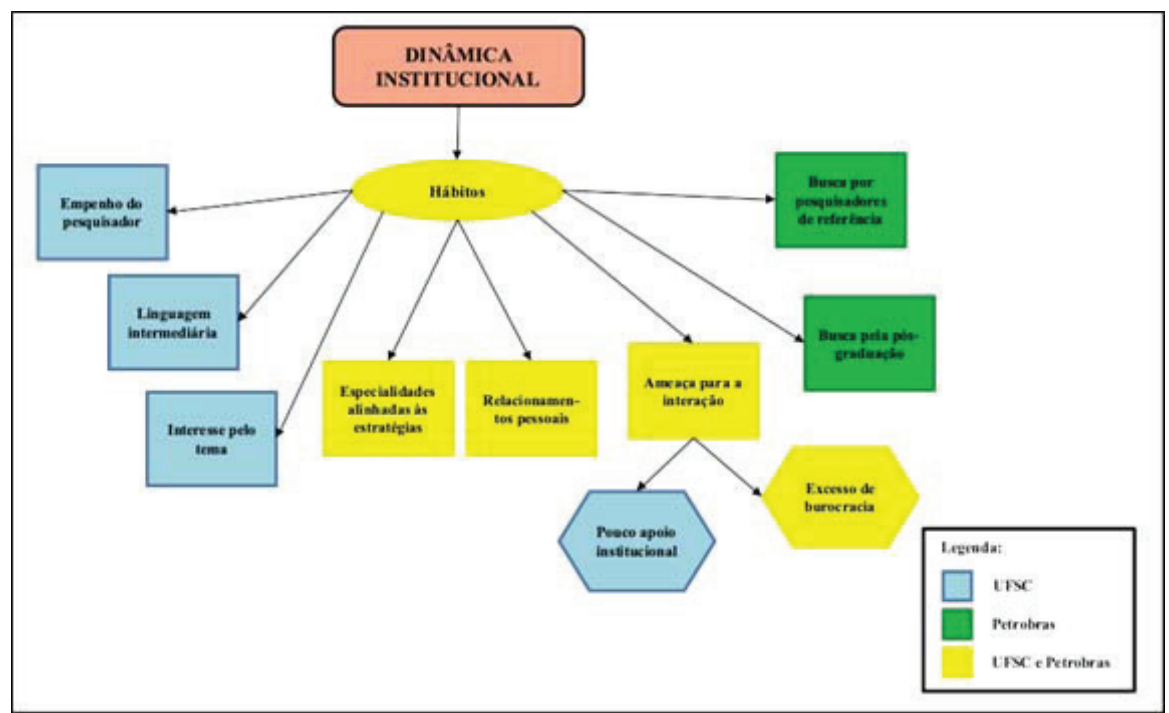

Fonte: Adaptado de Azevedo (2016).

A identificação dos hábitos da interação UFSC e Petrobras, exposta na Figura 1, compóe parte da dinâmica institucional em estudo. Os principais hábitos desta parceria citados pelos coordenadores da UFSC correlacionam-se à importância do relacionamento pessoal e confiança dos pesquisadores da UFSC e colaboradores da Petrobras; interesse da empresa pelo tema pesquisado; linguagem utilizada entre empresa e Universidade; empenho do pesquisador; e ameaça para a interaçáo (burocracia). Para os gerentes da Petrobras, os principais hábitos são a busca por pesquisadores de referência no tema de interesse da empresa, os quais apresentam 
especialidades alinhadas às suas áreas estratégicas; busca pelos programas de pós-graduação ligados aos pesquisadores que fazem parte dos projetos de P\&D; presença de relacionamentos pessoais, baseados na confiança mútua; e ameaça à interaçáo pelo excesso de burocracia dos órgãos de controle.

\subsection{Instituições}

As instituiçóes são essenciais para o crescimento econômico e para o processo inovativo, pois formam os meios de armazenamento e comunicação de informaçóes; assim como, constituem meios que dáo suporte a padróes de interação particulares, caracterizam-se como as "regras do jogo" e padrão de comportamento socialmente acordado (CASTELLI; CONCEIÇÃO, 2014). A importância das instituiçóes pode ser observada na expressão dos pesquisadores e diretoria da UFSC, os quais destacam a necessidade da institucionalização das parcerias e a relevância da instituição neste processo, tanto em virtude dos ganhos, como para resolução de problemas. "Existem algumas falhas no sistema, mas a lógica é necessária, qualquer parceria precisa ser institucionalizada [E7]". Para os gerentes da Petrobras a institucionalização da interação U-E é essencial: "Embora exista burocracia, creio que a lógica que envolve a institucionalização da interação é necessária, e aos poucos pode ser aperfeiçoada [E9]".

Nessa linha, a instituição contribui para reduzir a incerteza, fato este que a configura como essencial. No entanto, tal característica não garante sua eficiência, o que gera o conflito (NORTH, 1990). Em relação aos conflitos, cabe pontuar o contexto em que ocorrem as interaçóes U-E, as recentes modificaçôes da regulação nas Universidades, na Petrobras e na ANP, bem como os próprios desafios inerentes ao processo de interação, que culminam numa adaptação dentro das instituiçóes em virtude das novas regras. Para North (1991), as instituiçóes podem assumir a perspectiva de restriçôes informais (convençóes, códigos de conduta, tabus, costumes, tradiçôes, sançôes) ou regras formais (leis, constituiçóes e direitos de propriedade), e no presente estudo pode-se observar a presença destas restriçóes.

As restrições informais são decorrentes da informação socialmente transmitida e representam parte da herança cultural obtida e resultam de costumes, tradiçóes ou códigos de conduta e são mais resistentes e difíceis de serem alteradas (NORTH, 1990). Sob esta perspectiva, encontram-se presentes manifestações que retratam aspectos culturais contrários à interação U-E: "Há setores na Universidade que julgam que ela náo deveria ter parceria, e isso culmina com dificuldades na execuçáo de 
projeto" [E2]. Conforme depoimentos, há uma herança cultural na Universidade, por parte de alguns pesquisadores, de receio, hesitação e de intolerância à interação U-E, embora o movimento de parcerias tenha crescido na relação com a Petrobras nos últimos anos.

No tocante às regras formais, destacam-se vários regramentos. No âmbito da UFSC, encontra-se a Resolução Normativa n 47/CUN/2014, de 16 de dezembro de 2014, que dispóe de regras para as atividades de pesquisa e define padrōes a serem seguidos nos projetos. Outro regramento importante refere-se ao termo de cooperação entre a Petrobras e a Universidade, que foi elaborado em 2008 e define os principais aspectos desta interação. Em âmbito geral, cita-se a Lei n ${ }^{\circ} 8.666$, a qual institui normas para licitaçôes e contratos da Administração Pública com impacto no desenvolvimento de projetos em parceria. Em contexto setorial, a Resolução da ANP 33/2005, que impôs a condição de concessão de exploração de petróleo à obrigação de as empresas vinculadas ao setor Petróleo e Gás investirem 1\% da receita bruta anual de exploraçáo em atividades de P\&D, o que afeta a Petrobras e, por consequência, a Universidade, que recebe recursos em virtude desta legislação.

Outros marcos relevantes na política de ciência e tecnologia (C\&T) do Brasil afetam esta relação, como a Lei da Inovação e a Lei do Bem. A Lei da Inovação estabelece medidas que incentivam a inovação e a pesquisa científica e tecnológica no âmbito do ambiente produtivo, a fim de atingir a autonomia tecnológica e o desenvolvimento do sistema produtivo regional e nacional. A Lei do Bem, além de instituir o Regime Especial de Tributação para a Plataforma de Exportação de Serviços de Tecnologia da Informação - Repes, dentre outros, dispóe sobre incentivos fiscais para a inovação tecnológica.

Para os gerentes, estas medidas criam uma cultura de fomento à inovação, como segue: "As políticas, secretarias e estratégias são importantes, pois criam uma cultura de incentivo ao apoio à $P \& D$ e inovação. A Lei da Inovação e Lei do Bem foram mais um marco em relação à C\&T no país. Estas leis incentivaram, através de benefícios, maiores processos de interação U-E [E8]". A partir da aprovação destas leis, a Financiadora de Estudos e Projetos (Finep) deu início à modalidade de Subvençáo Econômica, o que propiciou o estímulo à inovação e parcerias entre universidades e empresas. Este quadro aponta que arranjos monetário-financeiros, através da Lei do Bem e Lei da Inovação, além da Resolução da ANP 33/2005, viabilizam financiamento para $P \& D$ e em extensão para a interação U-E.

Há também os órgãos de controle, o Tribunal de Contas da União (TCU) e a Controladoria-Geral da Uniâo (CGU), os quais fiscalizam a aplicação dos recursos 
utilizados na pesquisa. Parte desta fiscalização vincula-se ao que está definido pela Lei $N^{\circ} 8.666$, citada anteriormente. As regras formais integram a complexidade das sociedades e têm a capacidade de complementar e aumentar a eficácia das restriçóes informais e permitir que estas sofram alteraçóes, rescisóes ou sejam substituídas (NORTH, 1990, 1991).

Quanto à Resolução ANP 33/2005, tanto os pesquisadores como os gerentes da Petrobras reconhecem a importância desta legislação para quem realiza pesquisa na área de Petróleo e Gás no Brasil, como relatado: "Para todas as Universidades com professores e pesquisadores atuantes na área de petróleo e gás, a Resolução da ANP foi um evento importantíssimo nos cenários das Universidades no país [E2]". Os pesquisadores e diretoria da UFSC destacam, ainda, a importância da implantação do termo de cooperação estabelecido em 2008, modificando as regras anteriormente presentes nesta parceria. As regras estão em constante mutação, dão forma às instituições e estão relacionadas ao aprendizado contínuo. Sob enfoque institucionalista-evolucionário, o processo de aprendizado é path-dependent, enraizado e cumulativo e caracteriza-se como um processo dinâmico e evolutivo (EDQUIST, 2004).

Segundo os gerentes, a formulação do termo de cooperação permitiu nortear o processo e as parcerias firmadas para realização de P\&D, como elucidado a seguir: "O estabelecimento do termo de cooperação foi importante e resultado destes anos de interação, pois ficaram claras as regras relativas ao uso dos recursos, propriedade intelectual (PI) e desenvolvimento do projeto, esclarecendo os procedimentos relativos ao processo de interação [E8]." A criação do termo de cooperação é considerada pela UFSC e Petrobras como um avanço na institucionalização desta interação, pois significa maior facilidade no processo de negociação e um padrão de regramento a ser seguido e cumprido.

Os principais aspectos relativos à categoria de instituiçôes da análise da interação UFSC e Petrobras encontram-se na Figura 2. Assim, houve empenho da UFSC e Petrobras na direção da institucionalização da interação, a qual, aliada à perspectiva histórica que caracteriza este fenômeno, deu origem ao termo de cooperação em 2008, uma regra formal desta parceria considerada referência na realização de P\&D na interação U-E. Destacam-se ainda a Resolução 33 da ANP, o termo de cooperação e a Lei 8.666. A UFSC cita, ainda, a Resolução de pesquisa interna e a Petrobras ressalta a Lei do Bem e a Lei da Inovação. Nas restriçóes informais, os coordenadores da UFSC enfatizaram os aspectos culturais, os quais atrasam. em alguns casos, a aprovação dos projetos em parceria nos fóruns internos. 
FIGURA 2

Instituiçóes na interaçáo UFSC e Petrobras, 2016

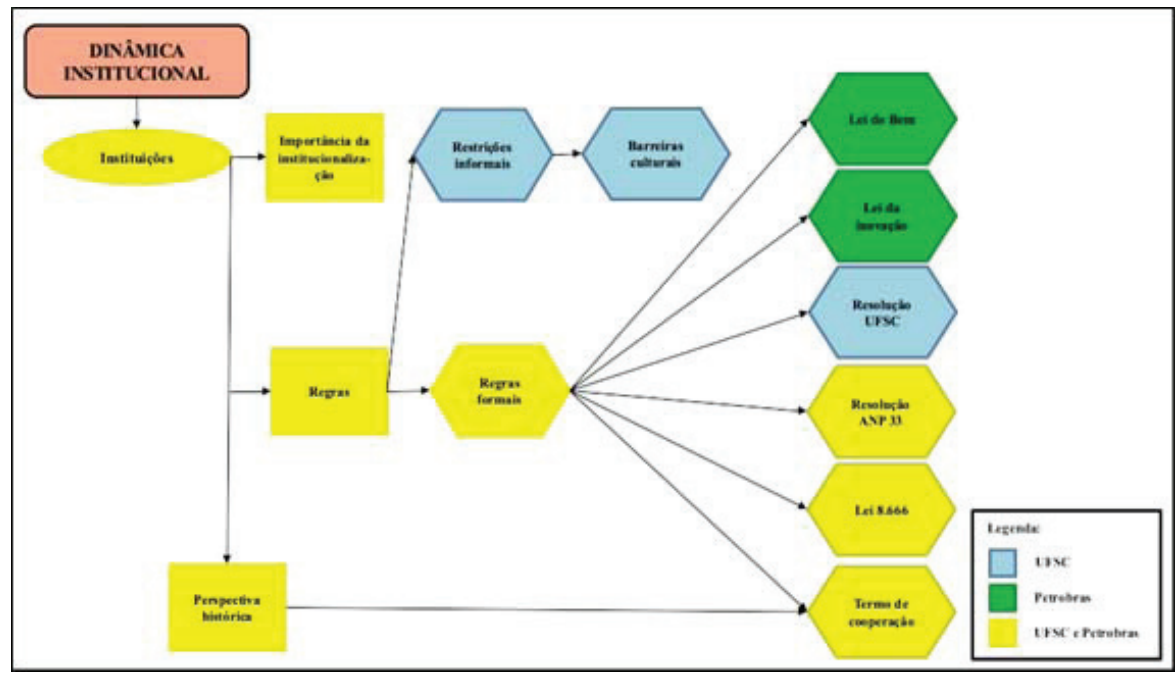

Fonte: Adaptado de Azevedo (2016).

\subsection{Tecnologias físicas}

A efetividade das atividades econômicas e o crescimento econômico correlacionam-se às tecnologias física e social. Inicialmente, as tecnologias físicas estão ligadas a procedimentos a serem realizados, os quais são normalmente dependentes de insumos e equipamentos (NELSON, 2008). No tocante à interação em estudo, os grupos de pesquisa da UFSC que interagem com a Petrobras são dotados de infraestrutura, especialmente em termos de laboratórios e equipamentos. A parceria possibilitou esta estruturaçáo e contribuiu para que os projetos entre UFSC e Petrobras se consolidassem ao longo desta trajetória.

A empresa criou toda uma infraestrutura para que os laboratórios dos grupos de pesquisa pudessem funcionar da melhor maneira possível e possibilitassem que vários projetos fossem realizados, pensando no futuro em longo prazo, desde a construção de prédios até aquisição de equipamentos de ponta e, principalmente, a manutenção de toda esta infraestrutura, visto que a Universidade não tem como mantê-la sozinha, em virtude do alto custo. A infraestrutura física permite que as instalaçóes sejam compartilhadas, promovendo ambiente de trabalho colaborativo e realização de pesquisa conjunta, consultorias e reunióes. 
Destaca-se, também, a possibilidade de realização de pesquisa situada na fronteira tecnológica. Segundo relato dos pesquisadores, sem a parceria com a Petrobras, este tipo de pesquisa poderia náo mais acontecer dentro da Universidade, conforme segue: "se nós tirarmos da Universidade os recursos que vem destes projetos, principalmente os da Petrobras, a Universidade não terá mais pesquisa no termo do que seja pesquisa de ponta [E2]". Embora os pesquisadores tenham a expertise na área de pesquisa, as tecnologias físicas são essenciais para que esta ocorra, e isto tem sido propiciado pela Petrobras, não só para pesquisas relacionadas à empresa, como para realização de outras pesquisas na Universidade, pois a infraestrutura montada torna-se disponível a qualquer pesquisa.

Os gerentes da empresa confirmam este investimento da Petrobras nas Universidades em termos de infraestrutura para realização de P\&D: "Nos primeiros anos após a regulamentação da cláusula de investimentos em P\&D da ANP em 2005, houve também um forte investimento nosso na criação de infraestrutura laboratorial de classe mundial na UFSC e em outras Universidades parceiras, capaz de atender a demanda de projetos de P\&D [E9].”

Conforme os gerentes da Petrobras, quando houve a regulamentação das atividades de $\mathrm{P} \& \mathrm{D}$ pela $\mathrm{ANP}$, não havia na época laboratórios e equipamentos, nem em quantidade e nem na qualidade requerida para os projetos. Assim, a Petrobras adotou duas estratégias: a criação da rede temática e o investimento em infraestrutura nas Universidades parceiras. Os laboratórios são utilizados para realização de diversos projetos com a Petrobras, com os demais participantes da rede temática e até mesmo em projetos com outras empresas. Dentre os projetos realizados, destacam-se: estudo de geofísica aplicada, gerenciamento e simulação de reservatórios, engenharia de poços, revitalização de campos maduros, modelagem e escoamento multifásico em tubulaçôes, centro de tecnologias em dutos, conservação e recuperação de ecossistemas e remediação de áreas impactadas (PETROBRAS, 2018).

\subsection{Tecnologias sociais}

As tecnologias sociais dizem respeito a mecanismos de coordenação, rotinas, padróes de organização da produção e divisão do trabalho. Estas são moldadas pelas instituições (NELSON, 2008). Segundo Nelson e Nelson (2002), a amplitude das tecnologias sociais engloba comportamentos ligados a diversas maneiras de organizaçâo da atividade e propicia uma compreensão das instituiçôes mais abrangente, como maneiras 
eficazes de desenvolver as atividades, no momento em que a cooperação humana é essencial. A partir disso, a intenção na pesquisa em relação às tecnologias sociais foi compreender como ocorre a organização da empresa, quanto ao estabelecimento da interação com a Universidade e a continuidade desta, incluindo o processo de comunicação durante a realização do projeto e a organização dos grupos de pesquisa para o desenvolvimento dos projetos de P\&D.

No que tange aos instrumentos utilizados para formalização da interação UFSC e Petrobras, surgiu como principal o termo de cooperação, mas também foram citados o contrato e prestaçấo de serviço. Nos relatos ficou evidente a participação das fundaçóes Feesc e Fapeu, ligadas à Universidade, no gerenciamento destes instrumentos. A compreensão foi diversificada pelos pesquisadores, alguns evidenciaram clareza em relação ao instrumento adotado no passado e no presente; enquanto outros apontaram pouca proximidade com o assunto, embora tenham interaçẫo há muitos anos.

Antes, as interaçóes da UFSC e Petrobras ocorriam via contrato ou prestação de serviço e, a partir de 2008, passou a ser adotado um termo de cooperaçáo, o qual foi acordado entre a Petrobras e a Associação Nacional dos Dirigentes das Instituiçóes Federais de Ensino Superior (Andifes). O termo de cooperação constitui modelo para projetos de $\mathrm{P} \& \mathrm{D}$, visto que contempla as necessidades da Universidade e da empresa, respeitando as questôes de PI, as quais são compartilhadas, como elucidado na discussão de instituiçóes e exposto na sequência: "A parceria UFSC e Petrobras ocorre por meio de um termo de cooperação estabelecido nacionalmente no ano de 2008. Este é um modelo para P\&D [E7]".

Este termo de cooperação surgiu a partir de um longo histórico de interação das Universidades com a empresa e, em especial, da UFSC com a Petrobras. São cerca de trinta anos de interação e, ao longo deste tempo, a experiência de ambas mostrou que a utilização deste tipo de instrumento para formalização dos projetos de P\&D seria mais efetivo do que os outros instrumentos como prestação de serviço, contrato e projetos de extensão. $\mathrm{O}$ instrumento de cooperação permite que as interaçóes empresa e universidades brasileiras sejam realizadas, garantindo termos que beneficiam as duas partes, como relatado pelo gerente da empresa: "O termo de cooperação permitiu avanço na institucionalização da interação da empresa com a UFSC e Universidades, pois foi esclarecido para os envolvidos o que pode ser feito e como deve ser a realização desta interação envolvendo P\&D [E9]".

O termo tornou-se um modelo de cooperação em $\mathrm{P} \& \mathrm{D}$, permitindo o avanço citado pelo gerente da empresa na institucionalização da interação UFSC e Petrobras. 
Com estas novas alteraçóes, o processo de interação é institucionalizado e bastante articulado, no qual a empresa, Universidade, agência reguladora e fundaçôes de apoio têm uma participaçáo alinhada no processo. O novo cenário das interaçóes é importante pois, conforme Metcalfe (2001), as instituiçóes dão forma ao crescimento do conhecimento científico, tecnológico e social. Estas são entendidas como estruturas e forças que moldam e sustentam as tecnologias sociais (NELSON, 2008).

O histórico de interaçóes da Petrobras com as Universidades contribui para se ter, de forma mais organizada, a tramitaçáo do projeto de P\&D. O Sigitec, criado em 2011 pela Petrobras e de amplo conhecimento dos envolvidos nesta interaçáo, envolve desde a inclusão de uma proposta de projeto até a entrega final de relatórios para empresa. Os gerentes da empresa e os pesquisadores da UFSC confirmam que a criação do Sigitec, uma governança de comitês tecnológicos, permite o acompanhamento das propostas e andamentos dos projetos. Propicia que os projetos de P\&D realizados em interação com as Universidades sejam idealizados e criados a partir das estratégias de negócio da empresa, presentes no planejamento estratégico e nos planos de negócio e gestáo. Possibilita que os grupos realizem o planejamento, acompanhamento e controle do desenvolvimento do projeto, bem como reunióes dentro do grupo e com a empresa e preparação de relatórios com resultados.

Além da preocupação da equipe alinhada às necessidades do projeto, as quais são expostas de maneira mais detalhada na sequência, cada projeto de pesquisa tem seus objetivos discutidos em conjunto pela UFSC e Petrobras, o que facilita tanto o seu planejamento como acompanhamento, realizado pelo grupo de pesquisa e pela empresa. De forma geral, conforme os pesquisadores, a divisão do trabalho nas equipes ocorre por especialidade, grau de conhecimento e titulação.

As equipes de pesquisadores são estabelecidas desde o princípio da formação da parceria, podendo variar seus componentes de acordo com o projeto. Há situação em que "[...] a equipe tem em torno de 50 pessoas (professores, alunos, pesquisadores, técnicos, engenheiros) [E6]”. Mas, há equipes pequenas, ao redor de dez pessoas e com apenas um professor responsável pelo projeto. Ressalta-se que há pesquisadores que trabalham em mais de um projeto ao mesmo tempo, vertical e transversalmente. Nessa via, prezam-se por pesquisadores contratados e professores com experiência acumulada, que garantam o treinamento, as contínuas trocas de experiências, a capacitaçáo dos membros da equipe e a continuidade do projeto.

Um ponto peculiar desta interação Petrobras e UFSC é a participação da empresa na equipe de trabalho, visto que há uma rotina de acompanhamento do projeto e realizaçáo de reunióes para o desenvolvimento de tecnologias, bem como 
uma participação efetiva da empresa no que tange aos caminhos a serem tomados pela pesquisa, os quais são discutidos em conjunto, como segue: "A empresa faz parte da equipe, porque é uma pesquisa aplicada, trabalhamos com isso. Nossos companheiros da Petrobras são participantes da equipe de trabalho [E4]”. Há acompanhamento da empresa por meio das reunióes periódicas para avaliar prazo estabelecido, procedimentos adotados, na superação de problemas, no alinhamento às demandas tecnológicas e na apreciação dos relatórios.

No tocante ao modelo de governança de P\&D, conforme a Petrobras (2014), a empresa atua $100 \%$ alinhada à estratégia corporativa em todos os níveis. O Plano Estratégico, o qual contempla pesquisas acerca das tendências tecnológicas e de cenários futuros, é o princípio dos trabalhos e desdobra-se até o nível de projetos de $\mathrm{P} \& \mathrm{D}$, em que é discutido e determinado em conjunto pelo Centro de Pesquisa e as áreas de negócio da empresa. Nesses termos, as tecnologias sociais são cruciais, pois quando são institucionalizadas criam condiçóes para a evolução das tecnologias físicas, e a coevolução proporcionada é vital para a consolidação dos SNIs, visto que propiciam a compreensão de como a inovação promove o crescimento econômico em cada contexto e momento histórico (NELSON, 2008; PEREIRA; DATHEIN, 2012).

A organização da empresa e dos grupos de pesquisa neste processo de interação tem aderência à ideia exposta por Conceição (2009), de que a associação da rotina com o conceito de tecnologia social ocorre principalmente em virtude de vincular-se ao envolvimento da habilidade humana em criar uma rota para o que deve ser realizado de maneira clara, fornecendo as razóes para tal escolha. Sendo assim, percebe-se a atuação da empresa e dos grupos na criação de caminhos que facilitam o desenvolvimento dos projetos de P\&D no processo de interação e, sobretudo, dos grupos no sentido de criar uma espécie de rota que garanta a continuidade dos projetos mesmo com a inserção de novos membros.

Em síntese, conforme a Figura 3, na ótica dos coordenadores da UFSC e dos gerentes da Petrobras foram identificadas como tecnologias físicas a criação da infraestrutura e a formação de redes temáticas. Os coordenadores e gerentes ressaltaram a manutenção desta infraestrutura como aspecto crucial para continuidade do desenvolvimento de tecnologias de fronteira. No âmbito das tecnologias sociais, os coordenadores da UFSC apontaram como rotinas do grupo de pesquisa a forma que a equipe é composta, a realização de reunióes periódicas, o desenvolvimento de projetos concomitantes e a utilização do Sigitec. Em relação à divisão do trabalho no laboratório, os coordenadores apontaram a realização da divisão por especialidade, 
grau de conhecimento e titulação. Por sua vez, os gerentes da Petrobras citaram como organização da empresa em relaçáo à pesquisa que será realizada, o acompanhamento e controle do projeto, as reunióes do laboratório, o sistema de gerenciamento e a realização de $\mathrm{P} \& \mathrm{D}$ aliada a estratégias de negócio da empresa.

\section{FIGURA 3}

Tecnologias físicas e sociais na interaçáo UFSC e Petrobras, 2016

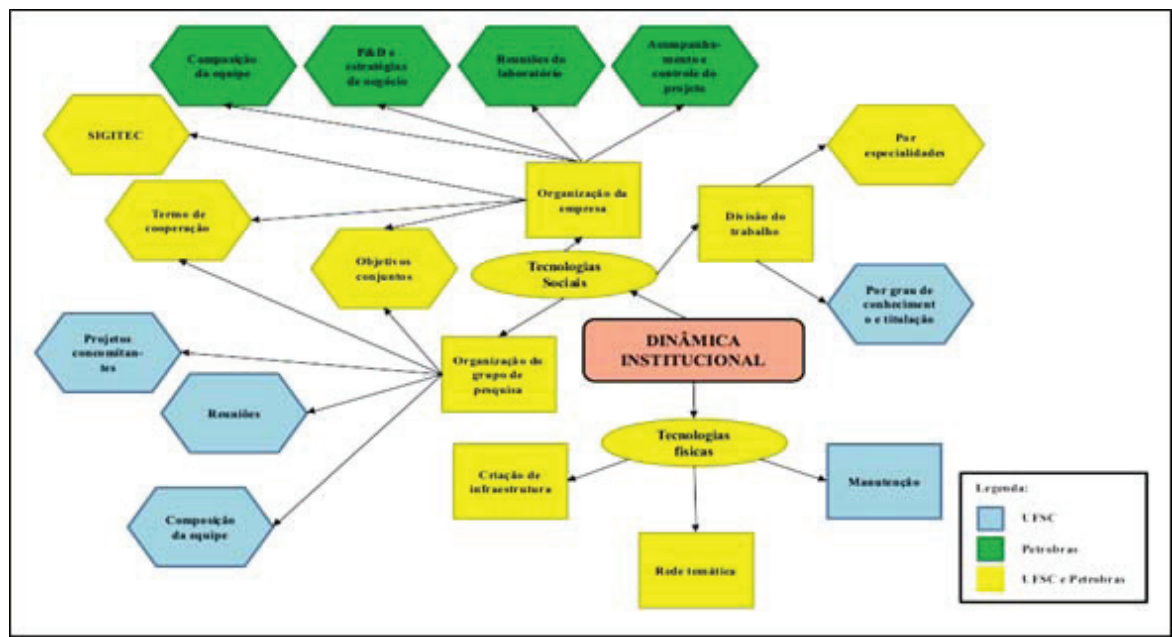

Fonte: Adaptado de Azevedo (2016).

\section{Conclusão}

A interação U-E é cercada de uma dinâmica institucional que revela a existência de hábitos, instituiçôes, tecnologias físicas e sociais referentes a esta parceria. Os "hábitos", como exposto por Hodgson (2010), decorrem de açôes, pensamentos e comportamentos que se repetem levando a um padrão de desempenho que se traduz num aprendizado mais rápido, mesmo com circunstâncias novas. Na parceria UFSC e Petrobras, os hábitos evidenciados foram a relevância do relacionamento pessoal, que de fato prevalece em decisóes desta interação U-E, considerando a ausência de edital da empresa para a realização de P\&D e a constante busca por pesquisadores de referência e de especialistas que se alinham aos estudos necessários para o enfrentamento dos desafios tecnológicos da Petrobras.

O conjunto de hábitos origina as "instituiçôes" e são os procedimentos habituais que propiciam poder e autoridade normativa estável. Na medida em que reproduzem 
os hábitos, as instituiçóes geram mecanismos de aceitação normativa. Neste curso, criaram condiçóes para a institucionalização da interação U-E expressa em processo histórico de construção de parceria e no estabelecimento de procedimentos e regras interativas UFSC e Petrobras. A interação firmada resultou em direcionamento das pesquisas - objetivos, equipe e resultados - reduzindo as incertezas que marcam o processo inovativo. Esta trajetória histórica construída permitiu que a parceria firmada fosse institucionalizada por meio de regulamentaçóes de P\&D da UFSC e da ANP, de regras formais que regem as parcerias no Setor de Petróleo e Gás e termo do acordo de cooperação que regulamenta a realização de P\&D.

$\mathrm{O}$ aprofundamento da análise da dinâmica institucional perpassa pela compreensão dos conceitos de tecnologia física e de tecnologia social, propostos por Nelson (2006, 2008). Dentre as "tecnologias físicas", citam-se a criação e a manutenção de infraestrutura (prédio, mobília, laboratório, equipamentos, computadores, projetos, entre outros), que consolidaram o processo de interação com a UFSC que garantem a realização de pesquisas por longo prazo. Destacam-se ainda as redes temáticas, as quais são desenvolvidos de forma colaborativa entre as instituiçóes reconhecidamente competentes nos temas selecionados, o que favorece o desenvolvimento tecnológico decorrente de novos projetos.

Quanto às "tecnologias sociais" que se expressam pela maneira de organizar e realizar, de forma cooperativa, pesquisa de interesse para o desenvolvimento, observa-se que grupos de pesquisadores da UFSC formam equipes, definem rotinas, atuam vertical e transversalmente e apresentam resultados que são acompanhados pelos representantes da Petrobras. Tais procedimentos possibilitam desenvolver habilidades e criar rotinas competentes dos procedimentos e com isso avançar em busca de novos produtos e processos.

A trajetória histórica perseguida de interação resultou na criação do Sigitec, um sistema de acompanhamento de coordenação de projetos de pesquisa, considerado uma tecnologia social, que permite que a empresa crie uma memória organizacional em termos de desenvolvimento de tecnologia. Este sistema, como a própria divisão dos grupos de pesquisa da Universidade e dos integrantes dos laboratórios do Centro de Pesquisas, Desenvolvimento e Inovação Leopoldo Américo Miguez de Mello (Cenpes), permite que a tecnologia se desenvolva de maneira célere, pois cada especialista está direcionado para sua atividade em específico, em virtude das constantes reuniōes conjuntas.

Destaca-se, ainda, como tecnologia social o termo de cooperação de P\&D, o qual foi resultado não só da parceria com a UFSC, mas também com outras 
universidades. Este foi elaborado a partir de um amplo debate entre os reitores das universidades brasileiras e representantes da empresa, que reconhecendo a relevância destes atores na geraçáo de novas tecnologias e no desenvolvimento nacional, acordaram um termo que é considerado por especialistas como uma referência para realização de $\mathrm{P} \& \mathrm{D}$ proveniente da interação U-E.

Diante do exposto, considera-se que o arcabouço institucionalista, em interação com o evolucionário, constitui importante caminho para estudo de interação U-E para a inovaçáo. A exemplo da abordagem evolucionária, a perspectiva institucionalista considera o processo de mudança da realidade econômica e social de forma cumulativa; a tecnologia constitui força motriz da transformação; as investigaçóes ocorrem sob condiçôes próprias e históricas específicas; e no ambiente que atua existem disputas, antagonismos, conflitos, incerteza e escolhas. Nessa linha, o estudo da interação UFSC e Petrobras demonstrou como a parceria firmada evoluiu e foi se aperfeiçoando no tempo, permitindo condições de melhoria na competência acadêmica e na obtenção de inovaçôes relevantes para a empresa.

Assim, reafirma-se a concepçáo de Nelson e Nelson (2002) de que as abordagens evolucionária e institucionalista possuem categorias que conversam, comungam e interagem entre si, não sendo epistemologicamente conflitantes. A junção de aspectos das abordagens institucional e evolucionária constitui fato importante, principalmente, no entendimento da inovação, uma vez que apresentam pressupostos comuns e complementares. Nesse sentido, Nelson e Nelson (2002, p. 267) afirmam: "As noted, increasingly evolutionary economists are coming to see 'institutions' as molding the technologies used by a society and technological change itself".

\section{Referências}

AZEVEDO, P. A interação UFSC e Petrobras para o desenvolvimento inovativo sob a óptica institucionalista-evolucionária. 2016. 508 p. Tese (Doutorado) - Universidade Federal de Santa Catarina, Centro Socioeconômico, Programa de Pós-Graduação em Administração, Florianópolis, 2016. Disponível em: http://www.bu.ufsc.br/teses/PCAD0974-T.pdf.

CARIO, S.A.F.; LEMOS, D.C.; SIMONINI, A. Avaliação da interação universidade-empresa. Revista de Economia, Curitiba, v. 37, n. especial, p. 239-278, 2011.

CASTELLI, J.R.; CONCEIÇÃO, O.A.C. Instituiçóes, mudança tecnológica e crescimento econômico: uma aproximação das escolas neo-schumpeteriana e institucionalista. In: ENCONTRO NACIONAL DE ECONOMIA, 42., 2014, Natal. Anais [...]. Natal, ANPEC, 9-12 dez. 2014. 
CONCEIÇÃO, O.A.C. O conceito de instituição nas modernas abordagens institucionalistas. Revista de economia contemporânea, Rio de Janeiro, v. 6, n. 2, p. 119-146, 2002.

CONCEIÇÃO, O.A.C. Tecnologia social e instituiçôes: uma relação conceitual simbiótica. Economia \& Tecnologia, ano 5, v. 16, p. 99-108, 2009.

DOSI, G. Mudança técnica e transformação industrial. Campinas: Ed. Unicamp, 2006.

D'ESTE, P.; PATEL, P. University-industry linkages in the UK: what are the factors underlying the variety of interactions with industry? Research Policy, v. 36, n. 9, p.1295-1313, 2007.

EDQUIST, C. Reflections on the systems of innovation approach. Science and Public Policy, v. 31, n. 6, p. 485-489, 2004.

GARCIA, R.; RAPINI, M.; CARIO, S.A.F. (org.). Estudos de caso da interação universidade-empresa no Brasil. Belo Horizonte: Cedeplar, UFMG, 2018.

HODGSON, G.M. El Enfoque de la economia institucional. Revista Análisis Económico, v. XVI, n. 33, p. 3-41, 2001.

HODGSON, G.M. Choice, habit and evolution. Journal of Evolutionary Economics, v. 20, p.1-18, 2010.

HODGSON, G.M. Qué son las instituciones? Revista CS. Cali-Colombia, n. 8, p.17-53, jul/dic. 2011.

JOHNSON, B.; LUNDVALL, B. Promovendo sistemas de inovação como resposta à economia do aprendizado crescentemente globalizada. In: LASTRES, M.H.; CASSIOLATO, J.E.; ARROIO, A. (org.). Conhecimento, sistemas de inovação e desenvolvimento. Rio de Janeiro: UFRJ; Contraponto, 2005. p. 83-130.

MALERBA, F. Sectoral System and Innovation and Technology Policy. Revista Brasileira de Inovação, Campinas, v. 2, n. 2, p. 329-375, 2003.

METCALFE, J. S. Institutions and progress. Industrial and Corporate Change, v. 10, n. 3, p. 561-586, 2001.

MONASTERIO, L.M. Guia para Veblen: um estudo acerca da economia evolucionária. Pelotas: Edufpel, 1998. 128 p.

MOWERY, D.C.; SAMPAT, B.N. Universities in national innovation systems. In: FAGERBERG, J.; MOWERY, D.C.; NELSON, R.R. (ed.). The Oxford handbook of innovation. New York: Oxford University Press, 2007. p. 209-239.

NELSON, R.R. As fontes do crescimento econômico. Campinas: Unicamp, 2006. 
NELSON, R.R. What enables rapid economic progress: what are the needed institutions? Research Policy, v. 37, n. 1, p. 1-11, 2008.

NELSON, R.R.; NELSON, K. Technology, institutions, and innovation systems. Research Policy, v. 31, n. 8-9, p. 265-272, 2002.

NELSON, R.R.; SAMPAT, B. Making sense of institutions as a factor shaping economic performance. Journal of Economic Behavior \& Organization, v. 44, n. 1, p.31-54, 2001.

NELSON, R; WINTER, S.G. Uma teoria evolucionária da mudança econômica. Campinas: Unicamp, 2006.

NIOSI, J. National systems of innovations are "x-efficient" (and x-effective). Why some are slow learners. Research Policy, v. 31, n. 8-9, p. 291-302, 2002.

NIOSI, J.; BELLON, B.; SAVIOTTI, P.; CROW, M. Les systèmes nationaux d'innovation: à la recherche d'un concept utilisable. Revue française d'économie, v. 7, n. 1, p. 215-250, 1992.

NORTH, D.C. Institutions, institutional change and economic performance. Cambridge University Press, 1990.

NORTH, D.C. Institutions. Journal of Economics Perspectives, v. 5, n. 1, p. 97-112, winter, 1991.

PEREIRA, A.J.; DATHEIN, R. Processo de aprendizado, acumulação de conhecimento e sistemas de inovação: a "co-evolução das tecnologias físicas e sociais" como fonte de desenvolvimento econômico. Revista Brasileira de Inovação, Campinas, v. 11, n. 1, p. 137-166, 2012.

PETROBRAS. Redes temáticas e núcleos regionais. Rio de Janeiro: Petrobras, 2018. Disponível em: http://sites.petrobras.com.br/minisite/comunidade_cienciatecnologia/portugues/redes_tematicas_superpc.asp. Acesso em: 5 dez. 2018.

SUZIGAN, W.; ALBUQUERQUE, E. M.; CARIO. S. (org.). Em busca da inovação: Interação universidade-empresa no Brasil. Belo Horizonte: Autêntica Editora, 2011.

TIGRE, P.B. Paradigmas tecnológicos e teorias econômicas da firma. Revista Brasileira de Inovaçâo, Campinas, v. 4, n. 1, p. 187-223, 2005. 


\section{Contribuiçáo dos autores}

A. Fundamentação teórico-conceitual e problematização: Paola Azevedo e Silvio Antônio Ferraz Cario

B. Pesquisa de dados e análise estatística: Paola Azevedo e Silvio Antônio Ferraz Cario

C. Elaboração de figuras e tabelas: Paola Azevedo e Silvio Antônio Ferraz Cario

D. Elaboração e redação do texto: Paola Azevedo e Silvio Antônio Ferraz Cario

E. Seleção das referências bibliográficas: Paola Azevedo e Silvio Antônio Ferraz Cario

Conflito de interesse: os autores declaram não haver conflito de interesse

Fonte de financiamento: os autores declararam não haver fonte de financiamento

\section{(c) (4)}

Este é um artigo publicado em acesso aberto (Open Access) sob a licença Creative Commons Attribution CC-BY, que permite uso, distribuição e reproduçấo em qualquer meio, sem restriçōes desde que o trabalho original seja corretamente citado 